\title{
The Role of Scleral Lens in Ectatic Corneas
}

Ilya Ortenberg, Shmuel Behrman

\section{ABSTRACT}

Scleral contact lenses can manage in treatment of keratoconus and ectatic corneal diseases. This article will review history, fitting technique and future of scleral lenses.

Keywords: Scleral lens, C orneal ectasia, Fitting.

How to cite this article: Ortenberg I, Behrman S. The Role of Scleral Lens in Ectatic Corneas. Int J Kerat Ect Cor Dis 2013;2(1):28-30.

\section{Source of support $\mathrm{Nil}$}

Conflict of interest: None declared

\section{DISCUSSION}

During the past decade the interest in scleral contact lens has increased immensely. Several publications, seminars, posters and workshops based on the understanding of scleral contact lens role in the management of irregular astigmatism and ectatic corneal diseases. The concept of optically neutralizing the cornea with a lens encl osed liquid reservoir trapped over its front surface was implied in several of L eonardo da V inci's sketches ${ }^{1}$ as early as 1480 . Fick ${ }^{2}$ described in 1888 'contact shells' were design of fluid reservoir over ecstatic corneal surface for vision rehabilitation. First scleral lenses made of glasses had no oxygen permeability and were very difficult to manufacture. The fitting of these lenses failed due to corneal hypoxia. Early practitioners failed to understand the need for corneal exposure to atmospheric oxygen. Polymethylmethacrylate (PM M A) in the early 1930 became a valuable tool for studying hypoxic corneal edema and advancing the understanding of corneal metabolism. ${ }^{3-5}$

The introduction and development of rigid gaspermeable materials led to increase popularity of scleral lenses once again. Several scleral lens designs made of highly oxygen-permeable materials have been described and published in the literature. ${ }^{6-9}$ Ezekiel $^{6}$ reported using of the gas-permeable materials $\left(16 \times 10^{-11} \mathrm{~cm}^{2} \mathrm{ml} \mathrm{O}_{2} / \mathrm{sec} \mathrm{ml} \mathrm{mm} \mathrm{Hg}\right.$ at $36^{\circ} \mathrm{C}$ ) in fenestrated scleral lenses for success vision rehabilitation (37 eyes). Rosenthal ${ }^{7}$ describe successful fitting within large series of patients with irregular astigmatism as an al ternative to penetrating keratoplasty by using the B oston scleral lens. Visser et $\mathrm{al}^{8}$ reported fitting scleral lenses for irregular astigmatism. Management of ocular surface diseases by using scleral lense principles and history of them has been showed by Pullum and Buckley. ${ }^{9}$

Keratoconus and ectatic corneal diseases are main indication for fitting rigid gas permeable (RGP) lenses in cases of visual rehabilitation. Corneal RGP contact lenses do not work due inadequate centration, unpredictable movement or poor visual acuity (Fig.1). Collaborative longitudinal evaluation of keratoconus (CLEK) study in the United States show that scar formation in keratoconus may lead to a loss in visual acuity and contrast sensitivity.

Scleral lenses do not touch the cornea. They are supported by the relatively normal sclera, they offer unique advantages over conventional RGP designs in cases of irregular astigmatism.

Patients with poor tolerance to corneal RGP contact lenses may find scleral lenses surprisingly comfortable. Corneas are very sensitive and innervated compare to bulbar conjunctiva under the scleral lens landing zone. Scleral lens can be an excellent option to restore vision, corneal clearance without any mechanical forces on the cornea involved, preventing any contact between the lens and the cornea by vaulting over it.

Fitting philosophy does not require the use of imaging equipment while with corneal RGP lenses corneal topographer became critical tools for success fitting. The fitting was based on the lens resting over external sclera and vaulting the cornea and limbus. Constant fluid reservoir between the lens and the cornea can mask the majority of irregular astigmatism. ${ }^{10} \mathrm{Corneal}$ clearance (Fig. 2) is primary

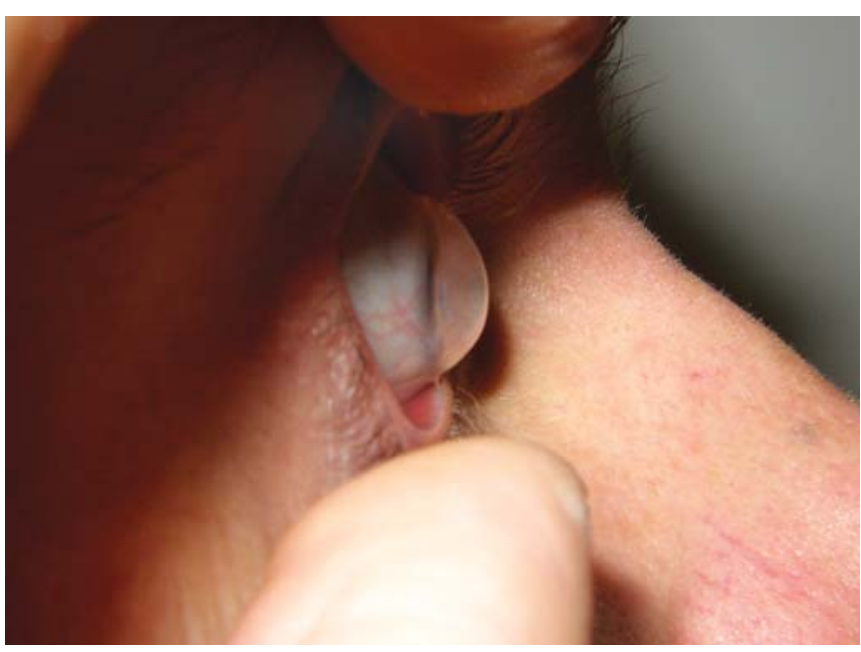

Fig. 1: Keratoglobus 

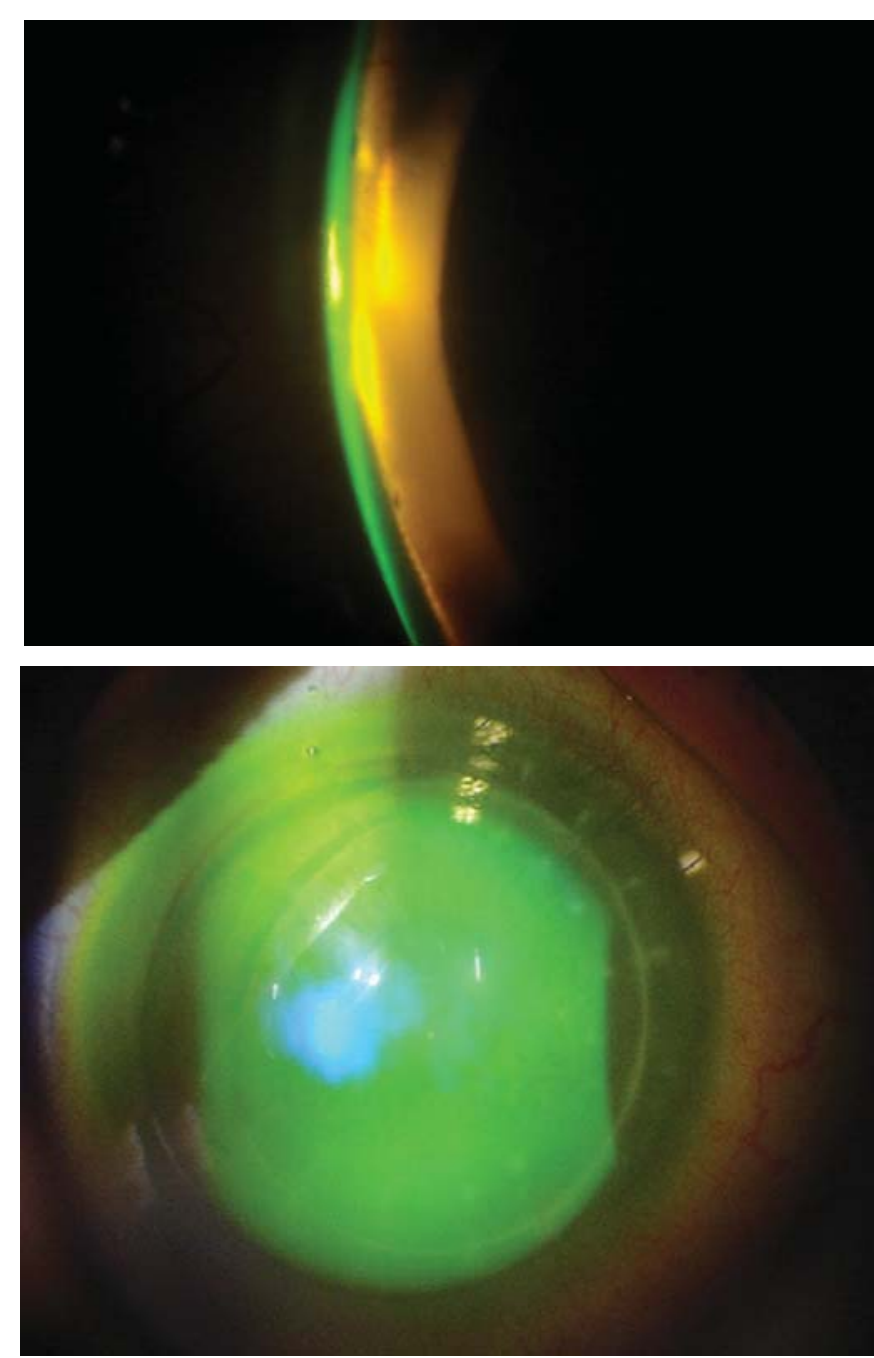

Fig. 2: Corneal clearance

advantage that scleral lenses have over R GP corneal lenses. Good fitting ensured a layer of half corneal thickness sal ine solution and the haptic portion loose enough to enable tear exchange, prevent blanching and edge off. W ell fitted scleral lens may have between 150 and 300 microns of central clearance. Patient must be checked with diagnostic lens filled with preserve free isotonic sterile saline solution and fluorescein. U sing slit beam for measuring central fluorescein pattern is necessary. Correct sagittal height is a most important key for good fitting lens. Sagittal height is dependent on a number of variables including lens diameter, radius of curvature of the cornea, asphericity of the cornea and the shape of the sclera portion. A paradox is that two eyes with the same keratometric values can have totally different sagittal heights. Increase or decrease of clearance by increasing or decreasing sagittal height become useful term instead 'flat or 'steep' in common routine procedure. If excessive clearance (Fig. 3 ) is apparent it means sagittal depth needs to be decreased, on the opposite side: a shallow fluorescein pattern (Fig. 4) on slit lamp examination means

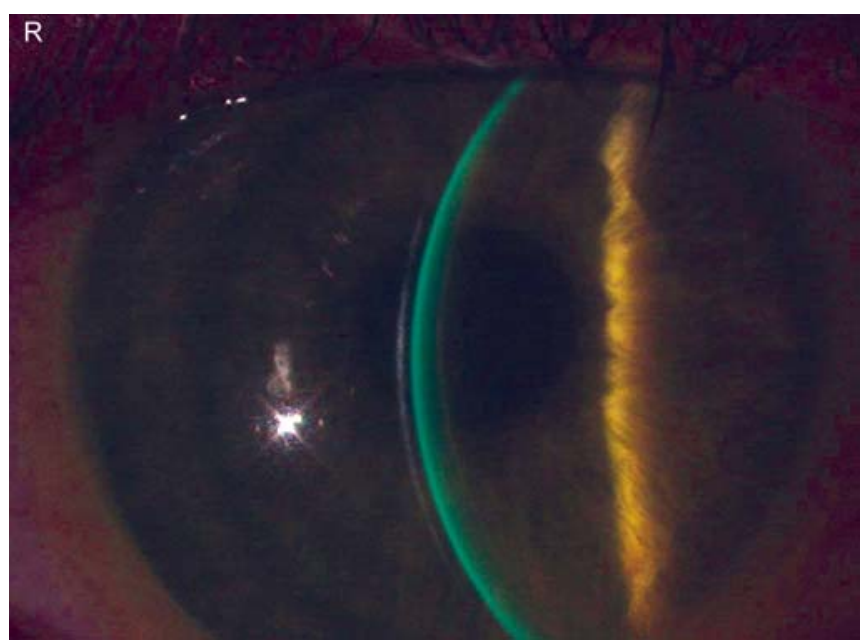

Fig. 3: Excessive clearance

increasing in sagittal depth necessary. Practitioners have to know that sagittal height depends on back optic zone radius (BOZR) and diameter of the chord. One parameter cannot be changed without considering the other.

Scleral contact lenses designed to vault the cornea and rest on the bulbar conjunctiva therefore blanching and impression not acceptable (Fig. 5). Paralimbal area underneath the lens will swell and become injected that could causes discomfort and reduced wearing time. It is very important to consider lens suction which obstructs tear flow under haptic portion of the lens. The haptic portion must be aligned as well as possible to the underlying sclera to prevent scleral compression as a result of lens suction. It can appear as limbal neovascularization, corneal edema, corneal transplant rejection and chemosis. ${ }^{11}$ B ridging over the entire cornea is rel evant because the importance of the limbal area where the stem cells are located.

One of the biggest threats to the scleral lens industry is the scleral lens industry itself. Fitting the scleral lens is not easy and it is not for everybody, which is something that recently has been frequently propagandized by some laboratories. While we have no good understanding of the sclera shape, almost all laboratories are jumping on this modality in a very opportunistic way. We need to be careful not to kill this modality before it even reaches adulthood. ${ }^{12}$

\section{CONCLUSION}

Scleral lenses have become an important part of modern specialty lens fitting. The scleral lens probably can be the best solution for medium to severe ectasia.

A natomic and physiological factors must be considered to avoid complications and enhance success. M ore knowledge is still required to fully understand the modality. 

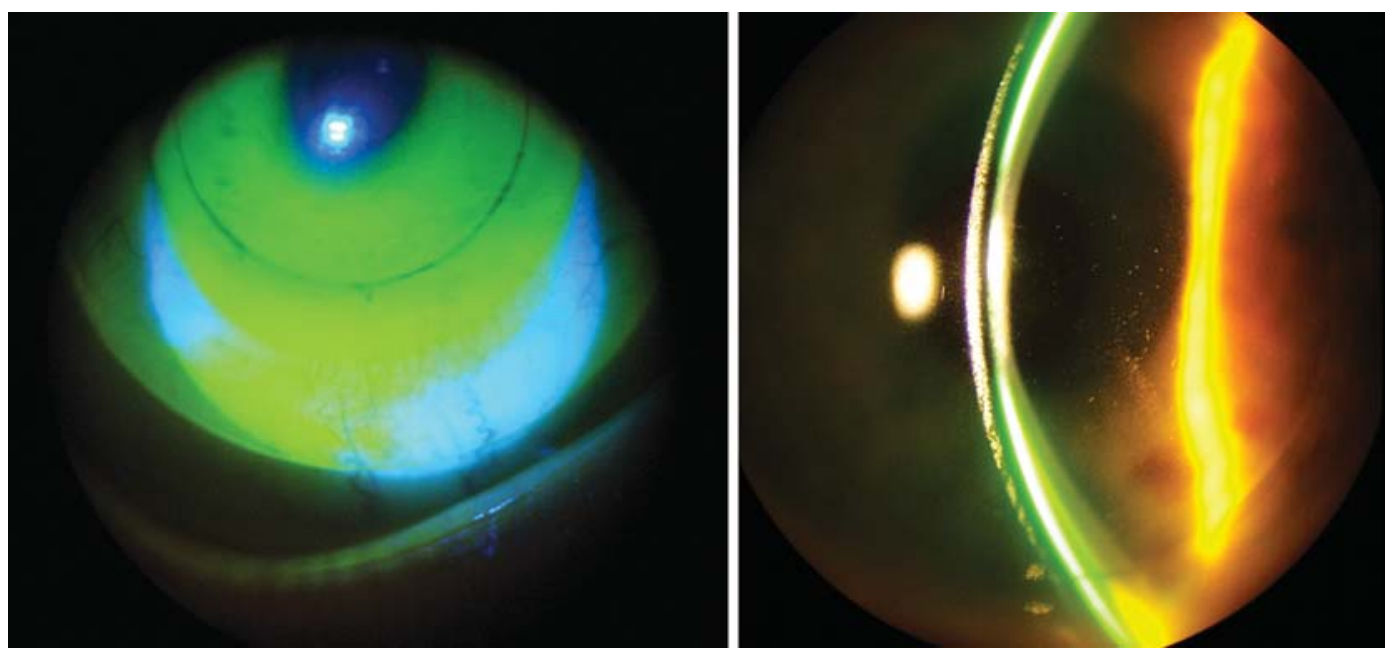

Fig. 4: Corneal touch
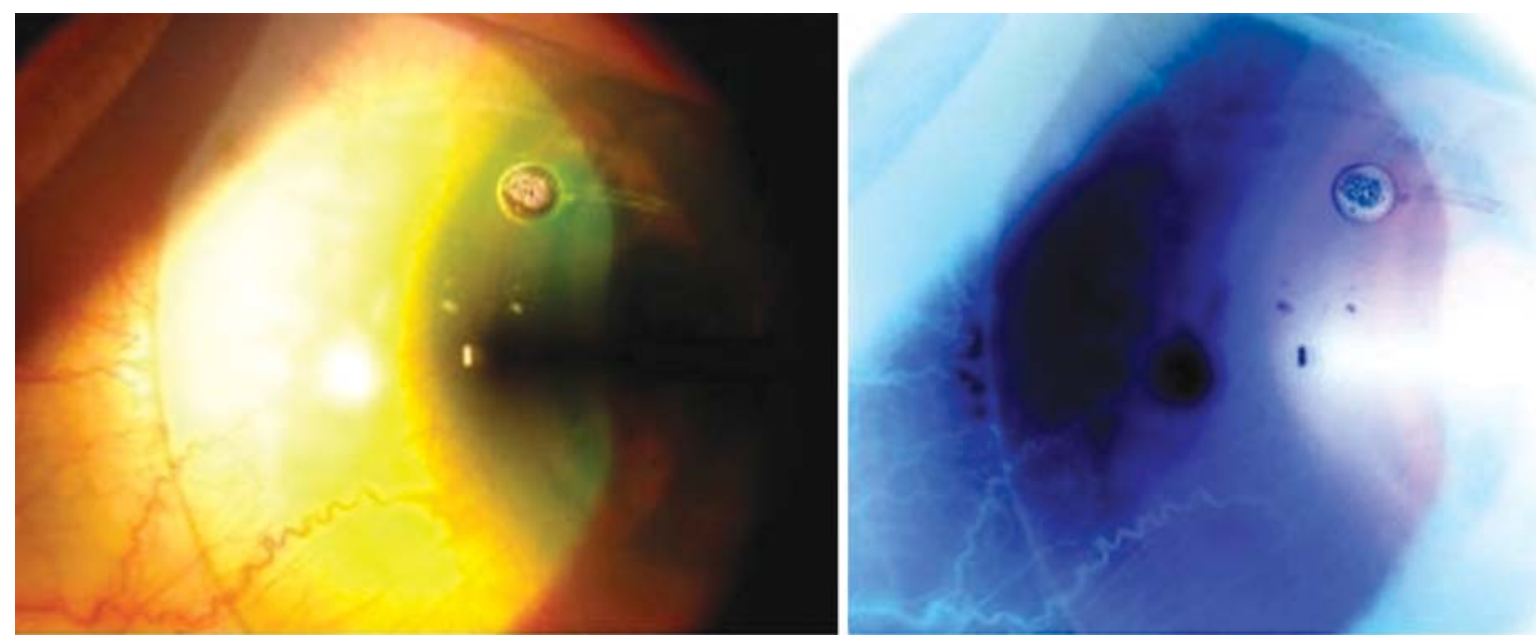

Fig. 5: Blanching

\section{REFERENCES}

1. Da V inci L. Codex of the eye, M anuscript D (circa 1508). A m J Optima 1953;30:41-44.

2. Fick AE. A contact lens (translated by $\mathrm{M}$ ay $\mathrm{CH}$ ). Arch Ophthalmol 1888;17:215-16.

3. Holden BA, Sweeney DF, Sanderson G. The minimal precorneal oxygen tension to avoid corneal edema. Invest O phthal mol V is Sci 1984;25:476.

4. Polse KA, B rand RJ, Cohen SR, et al. Stromal acidosis affects corneal hydration control. Invest Ophthalmol Vis Sci 1990;31:1542-54.

5. Bonanno JA. Contact lens induced corneal acidosis. CLAO J 1996;22:70-74.

6. Ezekiel D. Gas permeable haptic lenses. J Br Contact Lens A ssoc 1983;6:158-61.

7. Rosental P, Croteau A . Fluid-ventilated, gas-permeable scleral contact lens is an effective option for managing severe ocular surface disease and many corneal disorders that would otherwise require penetrating keratoplasty. Eye Contact Lens 2005;31: 130-34.
8. V isser ES, V isser R, van Lier HJ, Otten HM. M odern scleral lenses. Part II: Patient satisfaction. Eye Contact Lens 2007;33: 5-21.

9. Pullum K, B uckley R. Therapeutic and ocular surface indication for scleral contact lenses. O cul Surface 2007;5;40-48.

10. V isser ES, Visser R, van Lier HJ, Otten HM. M odern scleral lenses. Part II: Patient satisfaction. Eye Contact Lens 2007;33: $5-21$.

11. DeN aeyer GW . M odern scleral contact lens fitting. Contact $L$ ens Spectrum 2010;10:20-25.

12. W orp Evd. B eyond the cornea, Part II. G lobal Contact 2009;3: 28-30.

\section{ABOUT THE AUTHORS}

\section{Ilya Ortenberg (Corresponding Author)}

Optometrist, M icrolens Ltd, Tel A viv, Israel, e-mail: iliyagy@yahoo.com

\section{Shmuel Behrman}

Optometrist, M icrolens L td, Tel A viv, Israel 